\title{
PATTERNS OF DIAMOND AND KIMBERLITE INDICATOR MINERAL DISPERSAL IN THE KIMBERLEY REGION, WESTERN AUSTRALIA.
}

Smith, Chris. B.; Haebig, A.E. and Hall, A.E.

CRA Exploration Pty. Ltd., 21 Wynyard St., Belmont, Western Australia 6104.

Heavy mineral sampling of stream sediments and soils (loam) for diamonds and for kimberlite indicator minerals has been the most successful method for diamond pipe discovery in the twentieth century, being responsible for the discovery of the major pipe mines in Siberia, Botswana, and Australia. Yet few case histories have been documented of how the method works, or have described how its effectiveness changes with varying terrain conditions. This paper integrates a number of such cases to view them in the context of variations in the climate, geomorphology and geology of the Kimberley Region.

Kimberlites and lamproites within this Region (Jaques et al., 1986) have been emplaced at $1200 \mathrm{Ma}, 800 \mathrm{Ma}$, and $20 \mathrm{Ma}$, providing opportunity for liberation and widespread dispersion of diamonds and kimberlitic indicator minerals in the geological past as well as the present day. The Kimberley Region covers an area of some $300,000 \mathrm{~km}^{2}$ of tropical woodland savannah in northern Australia between latitudes $14^{\circ}$ and $18^{\circ} \mathrm{S}$. It consists of a high peneplain, the Kimberley Plateau, mostly of $300-800 \mathrm{~m}$ elevation, carved out of Proterozoic sediments and volcanics and sloping gently north eastwards towards the sea. The peneplain surface dates from the Cretaceous, perhaps even from the Proterozoic, and carries a good stream drainage network but one of only moderate energy. The Plateau is bounded by deeply dissected ranges (King Leopold Ranges in the south west, Durack Ranges and dissected ground of the Halls Creek Mobile Zone to the east), rising to over 900 metres elevation and characterised by rivers with high energy and erosive power. In the south west the ranges give way southwards to the arid lowland plains of the Great Sandy Desert, underlain by Phanerozoic sediments of the Canning Basin, with elevations typically less than 200 metres. The drainage regime here is poorly developed and of low energy.

The climate during the Cretaceous and early Tertiary was hotter and wetter than today. Most of Australia was covered by rain forest in which southern beeches (Notofagus sp.) were. prominent. Drainage on the peneplains would have been dominated by sluggish streams of low energy, moving a sandy bed load

(Wyrwohl, pers. comm.). A deep weathering profile was developed with formation of laterite, bauxite and silcrete where local geological bedrock conditions were appropriate; the silicification of the Pteropus kimberlite and lateritisation of the skerring pipe may date from this time. As much of the Kimberley Region is underlain by quartz-rich sandstone, ferruginous laterites are not as well developed as in other parts of Australia and the weathering profile is dominated by thin sand. By the late-Miocene to early-Pliocene, conditions became more arid and the Kimberley rain forest gave way to the more open woodland savannah of today. With less dense vegetation erosion rates increased, and the removal of the top 30-100 $\mathrm{m}$ of the lamproite crater volcanic sequence (and former 
tuff ring?) at Ellendale would date from this time. Likewise, the oldest ferruginous "A Terrace" diamondiferous gravels at Smoke Creek, downstream from the Argyle lamproite, are lateMiocene and testify to high-energy poorly-sorted conditions in this mountainous region (Deakin et al., 1989). Desertification took place during arid phases in the later Tertiary, with extensive dune development in the Great Sandy Desert, now vegetated over in the southern Kimberley. On the Kimberley Plateau fine red aeolian sand infilled the valleys and remnants are still preserved today. During the Quaternary, arid phases have oscillated with more pluvial inter-glacial times such as at the present day. Annual rainfall today varies from 1500 to 500 $\mathrm{mm}$, decreasing southwards towards the Great Sandy Desert. The rainfall is seasonal, most of it falling within the 4 month period from November to February. Furthermore most of that rain falls in short, sharp, heavy thunder storms. Consequently stream flow is subject to sudden flash floods, but for much of the year the smaller streams are dry. Sediment transport is therefore governed by the high energy flood events, and probably has been since the late-Miocene (e.g. Argyle alluvials).

Low grade regional metamorphism has affected the $1200 \mathrm{Ma}$ lamproites of Argyle and Lissadell Road. Extensive alteration has taken place during ascent and emplacement of lamproite and subsequently, with secondary replacement of virtually all

primary minerals except diamond and chrome spinel. Argyle today is being actively eroded and any former weathering profile has been removed. In this arid but high energy environment, diamonds and indicators in colluvium and proximal drainage have not been concentrated to grades above the primary content of the pipe. Chromite is about 6 times as common as diamond; pyrope, picroilmenite and chrome diopside are exceedingly rare. Numbers of chromite $+0.4 \mathrm{~mm}$ rapidly decrease downstream from a few hundred grains per $40 \mathrm{~kg}$ sample to a few tens by $5 \mathrm{~km}$ to sporadic occasional grains thereafter. Commercial-sized diamond extends downstream from Argyle for $150 \mathrm{~km}$ (Jaques et al, 1986), but economic quantities appear restricted to the first $30 \mathrm{~km}$ above the confluence of Smoke and Limestone Creeks with the very large Ord River (Lake Argyle). Coarse diamond decreases from 40 stones per tonne near source to some 2 stones per tonne by $15 \mathrm{~km}$ downstream. The occurrence and retention of smoke and Limestone Creek alluvial diamond deposits proximal to the pipe is due to good trapping by boulder gravel in the stream load, combined with favourable geomorphological trap sites.

Argyle-style diamonds (as identified by characteristic morphology, C isotopic content and mineral inclusion composition, Sobolev et al, 1989) are widely dispersed over $70,000 \mathrm{~km}^{2}$ of the Kimberley Plateau as a result of extensive earlier postulated Precambrian palaeo-dispersion. Erosion of the Argyle Pipe has been variously estimated from a few tens to less than $200 \mathrm{~m}$ and took place during the middle Proterozoic and Tertiary. However, several thousand metres of erosion of the nearby diamondiferous Lissadell Road Dyke and conceivably of other dykes and former pipes intruding the crystalline basement in this field could have contributed to palaeo-dispersion of Argyle-style diamonds. Similar broad alluvial dispersion of other diamond styles across the central-north Kimberley Plateau has resulted in confusing trails for explorationists (Sobolev et al., 1989). The local 800 Ma Pteropus and Aries Pipes have contributed some of these stones, but most are not directly sourced from any known pipe and the secondary distribution is 
thought to result from paleo-dispersion and reworking. Although humid tropical weathering caused extensive Mesozoic to early Tertiary lateritisation and silicification of kimberlites in the Kimberley Plateau, resulting in selective destruction of many indicator mineral species, clear trails of the more resistate minerals lead back to those kimberlites being eroded today. The most resistate mineral species have been diamond, followed by zircon and chromite. Ilmenite survives better than garnet and dominates the concentrates (Atkinson, 1989) but still suffers extensive oxidation in the laterite profile. Chrome diopside, orthopyroxene and olivine are rarely found even in soil overlying these kimberlites. Dispersal of indicators in loam is caused by soil creep, sheet wash, and wind action and generally does not exceed $400 \mathrm{~m}$ from a kimberlite, but trains of the more resistate chromite and zircon in the moderate energy stream drainage of up to $36 \mathrm{~km}$ are recorded by Atkinson (1989).

The Miocene lamproites of the West Kimberley are little eroded (less than $100 \mathrm{~m}$ ). Due to the low relief and aridity, characteristic of this area for most of post-emplacement time, the dispersion of indicators and diamonds has been dominately aeolian and is restricted typically to within $200 \mathrm{~m}$ of pipes. Some lateritisation has taken place but has not been sufficiently extensive for widespread destruction of indicator minerals at surface. A loam sample on an olivine lamproite may contain a few thousand chromite, but only some 10 garnets and perhaps 2 or 3 diamonds. Minerals characteristic of lamproite, e.g. potassic richterite and priderite, can be used as indicators close to source. However, the amphibole is not resistate to weathering, and its presence in this tropical environment, like chrome diopside, is restricted to loams virtually on top of pipes. Priderite, a groundmass mineral usually $<0.4 \mathrm{~mm}$ size, is generally too fine grained to be sought in dispersal trains. Poorly developed, low energy drainage, shows a 10-fold enrichment in indicator mineral concentrations close to a pipe, but downstream results fall off exponentially, diamond and garnet persisting for some $2 \mathrm{~km}$ and chromite for 10 $\mathrm{km}$ in $50 \mathrm{~kg}$ samples. Only very limited diamondiferous palaeogravel channels have been located to date, and.none have appreciable grade or proven economic significance. Any major eluvial/alluvial diamond concentrations formed in the Miocene have been eroded and transported away; local country rock sheds little gravel and bedrock trapping mechanisms are poor.

In summary, variations within the Kimberley Region show how chemical destruction of the least durable indicator minerals occurred under early Tertiary humid tropical weathering, with concentration of the resistates diamond, chromite and zircon, whereas arid environments gave lesser weathering effects. Concentration is promoted by low energy drainage, not by high energy erosive regimes, and aided by trapping features such as gravel and favourable physiography. Dispersal in loam by soil creep, sheet wash and wind generally does not exceed a few hundred metres. Dispersal trains are longest in streams with moderate to high energy and can extend for a few tens of $\mathrm{km}$. 


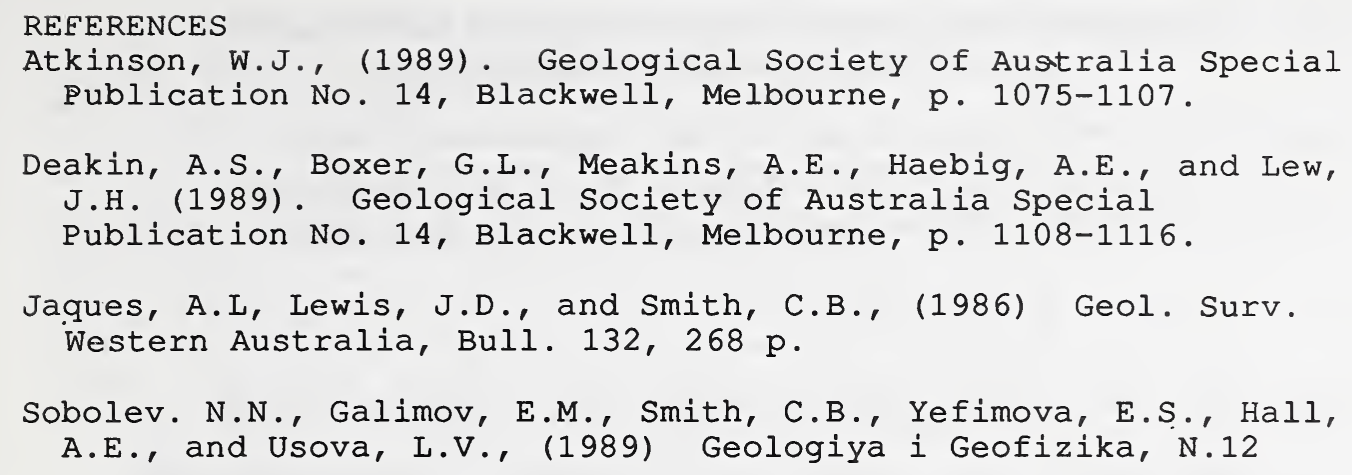

